\title{
LA DESIGUALDAD SOCIAL EN AMÉRICA LATINA Y EL CASO CHILENO
}

\author{
Ernesto Ottone y Carlos Vergara
}

\begin{abstract}
En muchos círculos académicos y políticos prevalece la idea de que la igualdad social es equivalente a una distribución igualitaria del ingreso primario. Los autores de este artículo plantean, por el contrario, que la idea de igualdad debe hoy vincularse más a una noción de bienestar que incluye cuatro dimensiones básicas: (a) acceso a los bienes de consumo y servicios básicos; (b) evolución de la pobreza; (c) acceso a las oportunidades, y (d) distribución del ingreso. Se sostiene, asimismo, que la lucha por la igualdad debe
\end{abstract}

ERnESTo OtTone. Estudió Sociología en la Universidad Católica de Valparaíso y obtuvo el Doctorado en Ciencias Políticas en la Universidad de París III "La Sorbonne Nouvelle”. Actualmente es Secretario Ejecutivo Adjunto de la Cepal. Entre 2000 y 2006 fue Director de análisis estratégico de la Presidencia durante el gobierno de Ricardo Lagos. Anteriormente se había desempeñado en la Cepal y la Unesco. Autor de numerosas publicaciones, entre sus últimos libros están Osadía de la Prudencia. Un Nuevo Sentido del Progreso, con Crisóstomo Pizarro (Fondo de Cultura Económica, 2003); La Modernidad Problemática. Cuatro Ensayos sobre el Desarrollo Latinoamericano (Editorial JUS, México, 2000).

Carlos Vergara. Sociólogo de la Pontificia Universidad Católica de Chile. Realizó los estudios de Doctorado en Sociología en la Universidad de Warwick, Inglaterra. Actualmente trabaja en Cepal. Ha sido académico de la Universidad Católica de Valparaíso y de la Pontificia Universidad Católica de Chile. Fue asesor del Presidente Lagos durante todo su mandato. Entre sus últimas publicaciones están Ampliando Horizontes, junto a E. Ottone (Random House Mondadori, 2007), y los artículos "Hacia un Sistema de Indicadores de Cohesión Social en América Latina” con J. C. Feres (en Ana Sojo y Andrés Uthoff, eds., Cohesión Social en América Latina y el Caribe, 2007), y "Progessivism in Politics”, con E. Ottone (en Progressive Politics, 2004). 
hacerse en el marco de las reglas de la democracia y el pleno ejercicio de las libertades.

Tras una breve contextualización de la desigualdad y la concentración de ingresos en América Latina, se analizan las cuatro dimensiones señaladas en la región y luego en Chile.

\section{INTRODUCCIÓN}

L

legitimidad de la aspiración a la "igualdad social”, tal como la entendemos hoy, es un fenómeno relativamente reciente en la historia de la humanidad. Adquiere centralidad teórica y política en el siglo XIX y se expande a través de los avatares del siglo XX, siendo objeto de lecturas e interpretaciones muy distintas, a veces contrapuestas, desde visiones extremas que no la conjugan con la libertad individual hasta aquellas que la reducen a la mera igualdad jurídica, haciendo caso omiso de su dimensión económica y social.

Para entender los desplazamientos de este desarrollo conceptual, resulta curioso reproducir una interpretación de la igualdad que nos lega el siglo de las luces, la voz "igualdad” del Diccionario Filosófico de Voltaire: “Cada hombre, en el fondo de su corazón, tiene el derecho a creerse enteramente igual a los otros hombres; de ello no se sigue que el cocinero de un Cardenal deba ordenarle a su amo que le prepare la comida, pero el cocinero puede decir 'yo soy un hombre como mi amo, yo nací como el entre llantos, el morirá como yo en las mismas angustias y ceremonias. Los dos hacemos las mismas funciones animales. Si los turcos se apoderan de Roma, y si yo me convierto en Cardenal y mi amo en cocinero, yo lo tomaría a mi servicio'. Todo este discurso es razonable y justo; pero, en espera que el Gran Turco se apodere de Roma, el cocinero debe cumplir con su deber o toda la sociedad humana se pervertirá”.

Recordemos que a mediados del siglo XIX la esclavitud todavía era un fenómeno extendido, y que hasta hace pocos siglos el mundo estaba dominado por una pobreza omnipresente, como lo señala Thomas Hobbes en el Leviatán (1651): la vida era “solitaria, miserable, hostil, animalesca y breve" 1 .

Hoy en día la idea de igualdad se liga a la noción de ciudadanía que nace con la revolución francesa, el Estado moderno y la revolución indus-

${ }^{1}$ Cita tomada del libro de Amartya Sen, Identitá e Violenza, 2006, p. 133. 
trial. La humanidad ha dado grandes pasos - tanto en lo conceptual como en los hechos- en materia de igualdad social. Pero estos avances no han sido ni serán lineales. Tampoco previenen eventuales retrocesos o procesos de barbarie.

América Latina no escapa a este recorrido lleno de vicisitudes. Debido a nuestra historia tan esquiva en solidez democrática, vigencia de la libertad y niveles deseables de igualdad, los latinoamericanos estamos obligados a pensar el tema de la desigualdad sin separarlo jamás del tema de la democracia y de la libertad.

Ello nos aleja de las visiones "optimistas" de los años sesenta que nos decían que lo importante era tener una cierta cantidad de inversión para generar el crecimiento de la economía (Rostow), que ello traería aparejado mayores niveles de equidad social (Kusnetz), y que, finalmente, todo ello derivaría en mayor democracia (Lipset). Nos aleja también de aquellas visiones absolutistas y excluyentes, y nos hace rechazar la igualdad como un absoluto. La igualdad no es sinónimo de igualitarismo y menos de uniformidad. Igualitarismo y libertad individual absoluta se excluyen; no así la libertad y la igualdad.

De allí que sigamos a Norberto Bobbio en su aspiración a una democracia "exigente", "a demandar de la democracia un compromiso a la vez con la libertad, con una mayor igualdad en las condiciones materiales de vida [...] Una cierta voluntad igualitaria en el sentido de usar el poder del Estado para contribuir a morigerar las desigualdades materiales más manifiestas e injustas así no más sea porque la presencia en una sociedad cualquiera de tal tipo de desigualdades puede tornar ilusorio y vacío para quienes las padecen el disfrute y el ejercicio de las propias libertades"2.

Está fuera de dudas la aspiración hacia una mayor igualdad de los latinoamericanos. Así lo muestran, de las más diversas maneras, las mediciones demoscópicas y también el discurso y el accionar político en la región. Lo que es menos evidente es la claridad del análisis sobre el fenómeno de la desigualdad y los caminos para avanzar hacia sociedades más igualitarias.

\section{AMÉRICA LATINA: CONTEXTUALIZACIÓN}

\subsection{Los ingresos}

América Latina es un continente de ingresos medios, cuya imagen de sí misma, desde siempre, parece haber estado definida por la idea del

\footnotetext{
${ }^{2}$ Bobbio, Norberto: El Futuro de la Democracia, 1986.
} 
FIGURA N ${ }^{\circ}$ 1: $\quad$ PIB PER CÁPITA EN SIETE REGIONES DEL MUNDO

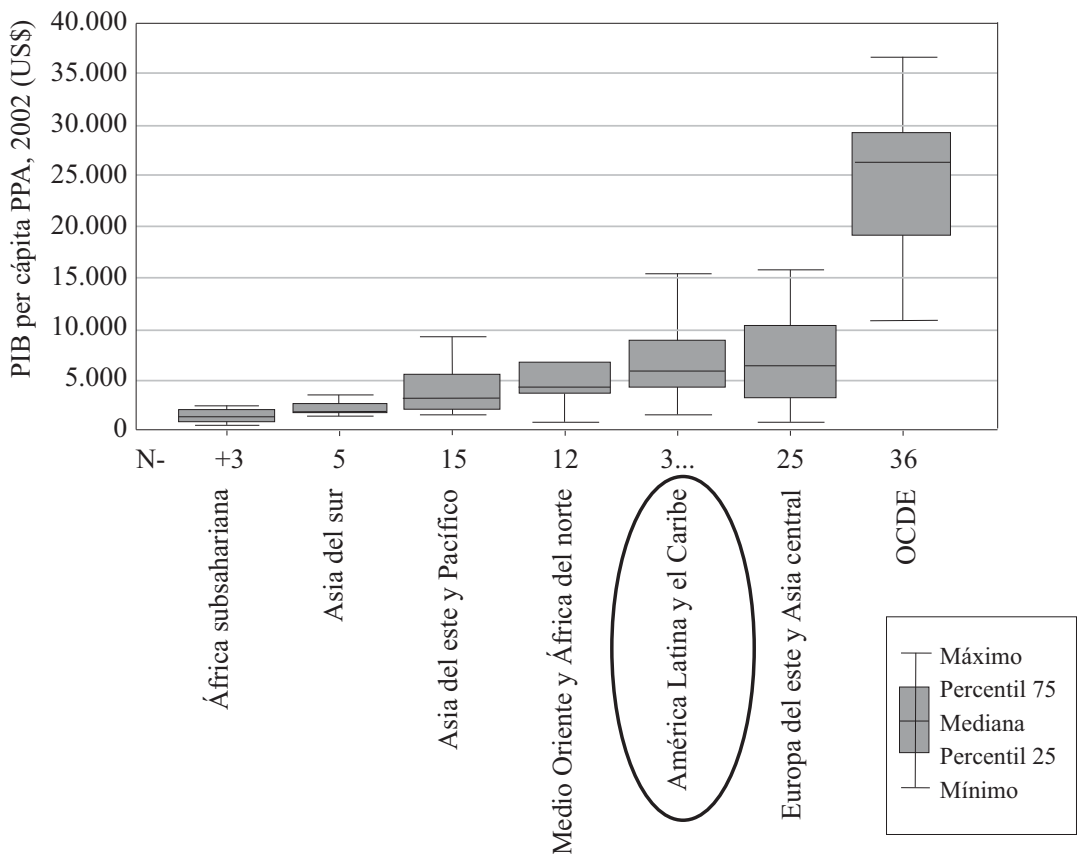

Fuente: Feres, Juan Carlos y Carlos Vergara: "Hacia un Sistema de Indicadores de Cohesión Social en América Latina”, 2007.

“atraso"3. No somos distintos a Europa, sólo que venimos desde atrás, estamos atrás, y nuestro destino pareciera estar atrás. Somos parecidos, pero atrasados. No somos los primeros, pero tampoco los últimos de la clase. Ocupamos ese espacio difuso entre las naciones más pobres del planeta y la realidad de los países de la OCDE. No es una región calificable de “pobre”, como buena parte de África, pero tampoco es una región desarrollada.

El PIB per cápita de América Latina es similar al de Europa del este y de Asia central, pero es del orden de un quinto de aquel que muestran los países de la OCDE, y más de dos veces el de África subsahariana.

De otra parte, América Latina es la región con la más alta desigualdad de ingresos del mundo. Cierto es que cuando hablamos de América Latina nos referimos a cifras promedio que incluyen realidades nacionales muy diferentes, sobre todo en materia de niveles de pobreza e ingresos.

${ }^{3}$ Afirmación de historiador Tulio Halperin Dongui en conferencia pronunciada en la Cepal con ocasión de la Séptima Cátedra Raúl Prebisch, agosto 2007. 


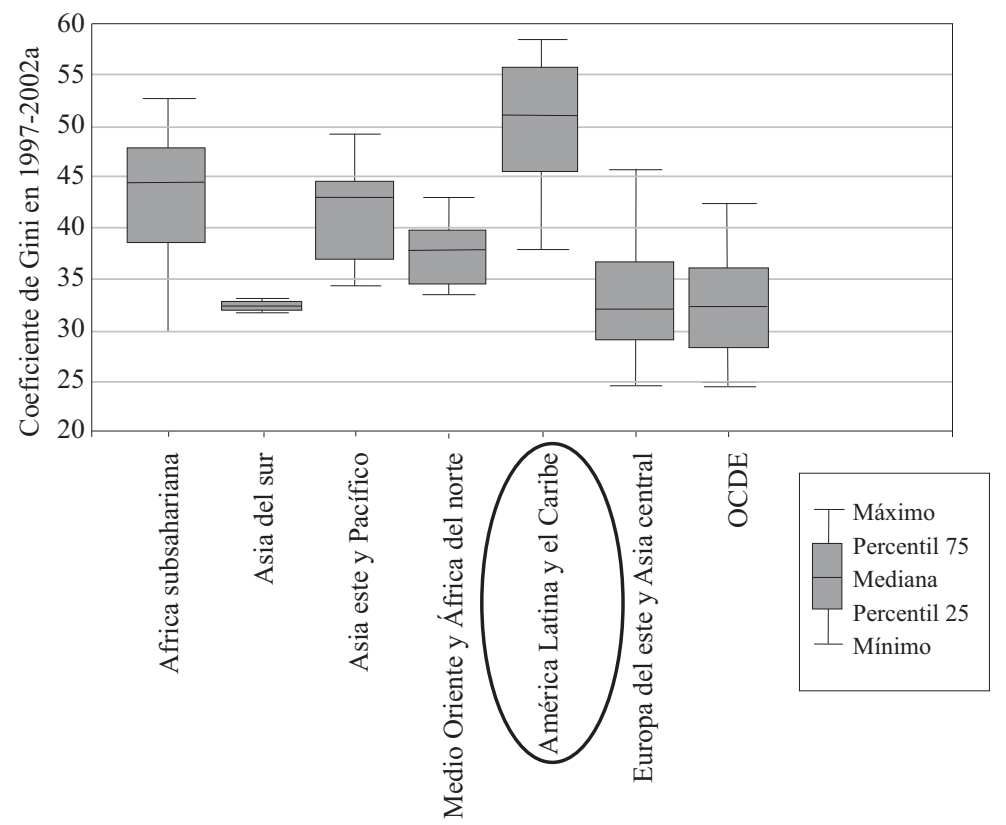

Fuente: Feres, Juan Carlos y Carlos Vergara: "Hacia un Sistema de Indicadores de Cohesión Social en América Latina”, 2007.

Cierto es que el más igualitario de los países de América Latina tiene una distribución del ingreso más desigual que el más desigual de los países desarrollados de la OCDE. Pero también es verdad que una persona pobre de América Latina, con sus ingresos, tiene mucho más acceso a bienes y servicios que una persona pobre de Asia del sur. Una sociedad homogéneamente pobre y, por tanto, igualitaria en la pobreza no es necesariamente más virtuosa que otra de ingresos medios pero con mayor dispersión y, en consecuencia, menos igualitaria.

\subsection{La desigualdad es histórica}

Como se señala en muchos trabajos sobre este tema, la desigualdad de los ingresos en América Latina tiene su base y su origen en una etapa muy lejana de su historia y se relaciona con las características propias que asumió el proceso de colonización (básicamente español y portugués) en el continente. 
Así las cosas, la propiedad de los principales activos siempre fue extremadamente concentrada: la propiedad de la tierra desde siempre (cabe recordar la institución de la encomienda, mediante la cual la Corona entregaba enormes extensiones de tierra con trabajo semiesclavo incluido); la propiedad de las riquezas mineras, oro y plata en la época colonial, hasta las riquezas de estaño y cobre en la segunda mitad del siglo XX, y la concentración de los activos educacionales que se arrastra hasta el día de hoy en la mayoría de los países de la región.

Esta concentración histórica de los activos productivos ha sido acompañada desde siempre también por la concentración de la influencia social y el poder político en las mismas elites que concentran el poder económico. El contrato social que hizo posible la construcción del Estado de bienestar en Europa, no tuvo lugar en América Latina. Sólo en algunos países, básicamente en aquellos de urbanización temprana, se produjeron procesos parciales de protección social que lograban incluir a sectores medios y populares urbanos con alta capacidad de presión. La discriminación de clases sociales, la discriminación étnica y discriminación de género mantenían la exclusión de amplios sectores de la población. Las experiencias de crecimiento alto y acelerado de muchos países de industrialización reciente en otras latitudes tuvieron en general condiciones sociales de base más igualitaria que aquellas que han primado históricamente en Latinoamérica.

En consecuencia, la desigualdad de ingresos que caracteriza a América Latina no es producto del desarrollo reciente de la región, no es producto de la globalización, sino que ha convivido con todos los modelos de desarrollo latinoamericanos de los últimos 200 años.

La globalización no produce la desigualdad, sino que la viene a reforzar en sus aspectos más relacionados con la modernidad, como lo es la educación. Como se señala en un documento reciente, “[...] las causas estructurales que explican los altos niveles de inequidad, vale decir, que constituyen un sistema de perpetuación y agudización en el tiempo de la brecha de ingresos entre distintos grupos sociales, radican sobre todo en (las diferencias en) el acceso a activos, entendiendo por tales el acceso a educación, conocimiento y empleos de calidad y, en medida diversa, el acceso a otros activos como tierra, capital y financiamiento, y también ciertos rasgos demográficos y adscriptivos. Tales son los eslabones que reproducen la inequidad, dado que son altamente transmisibles de una generación a la siguiente y, por ello, perpetúan la mala distribución del ingreso pese a los esfuerzos del Estado en invertir para apoyar a los grupos más pobres. En las últimas dos décadas se agrega el efecto de los ciclos de expansión y con- 
tracción de la macroeconomía, que ha resultado en mayor concentración de los ingresos"4.

Esta desigualdad, al igual que la pobreza, se agrava en los ciclos económicos negativos y mejora muy poco en los ciclos positivos: la experiencia demuestra que cuando la economía crece los ricos ganan mucho y los pobres, si bien ganan, ganan poco. Pero cuando cae el crecimiento, los ricos casi no pierden y los pobres pierden mucho. En este sentido, las políticas fiscales pro cíclicas han favorecido el fenómeno de la desigualdad en América Latina.

\section{EL DEBATE SOBRE LA DESIGUALDAD: ¿DE QUÉ SE TRATA?}

El contexto antes señalado hace indudablemente más complejo el debate sobre cómo alcanzar niveles más altos de igualdad en las sociedades contemporáneas, particularmente en una América Latina muy desigual.

\section{Cuando hablamos de desigualdad, ¿de qué queremos hablar en rea-} lidad?

Esping-Andersen señala que la cuestión central tiene que ver con las oportunidades. Lo que hay que desentrañar, según este autor, es si acaso las crecientes desigualdades de ingreso que se presentan hoy en día van de la mano con una creciente desigualdad de las oportunidades entre las generaciones. Agrega, además, que la evidencia sugiere que no hay un empeoramiento de las oportunidades de movilidad y que, en algunos pocos países, las oportunidades incluso han mejorado ${ }^{5}$.

Otros autores sostienen que hay que poner la mirada en cómo mejoran (o empeoran) las oportunidades y las condiciones de vida del segmento más pobre y vulnerable de la población, y menos en analizar las distancias entre ricos y pobres ${ }^{6}$.

Otros, siguiendo a Rawls, sostienen que lo justo es que - cuando aumente la riqueza total— todos los segmentos de la sociedad ganen algo y no que todos ganen lo mismo. Lo injusto, en este caso, no es que unos ganen más que otros sino que haya quienes no ganen nada. Se trata, como sostiene Agustín Squella, de llegar a un punto "donde no todos sean iguales en todo, pero todos sean iguales en algo".

La idea de Luhman y Habermas según la cual las sociedades se componen cada vez más de subsistemas relativamente autónomos permite

\footnotetext{
${ }^{4}$ Machinea, J. L. y M. Hopenhayn: "La Esquiva Equidad en el Desarrollo Latinoamericano. Una Aproximación Estructural, una Aproximación Multifacética”, 2005.

${ }^{5}$ Esping-Andersen, Gosta: "Inequality of Incomes and Opportunities”, 2005.

${ }^{6}$ Véase, por ejemplo, Atkinson, Robert D.: "Inequality in the New Knowledge Economy”, 2005.
} 
pensar en la noción de la "igualdad compleja”, según la cual las desigualdades no se darían de forma homogénea en todos los terrenos. En otras palabras, no somos "igualmente desiguales" en todo. Así, por ejemplo la desigualdad en el acceso a ciertos bienes de consumo material, y particularmente simbólicos, no se reproduce en el mismo grado que la desigualdad en los ingresos ${ }^{7}$.

Por cierto hay una desigualdad proveniente de la distribución primaria del ingreso, y que tiene que ver con la cuantía de recursos con que las familias cuentan para proveerse de aquellos bienes y servicios que se transan en el mercado. Es cierto, no todos ganan lo mismo y, por tanto, no todos tienen acceso a la misma cantidad y calidad de bienes. Y, también es cierto, hay algunas diferencias que son irritantes.

Pero también es cierto que existen servicios que no están en el mercado y cuyo acceso y disfrute están asociados al bienestar. La experiencia de los Estados europeos así lo demuestra.

Lo cierto, en todo caso, es que no es pertinente ni correcto hacer sinónimos las nociones de desigualdad social con la distribución de los ingresos provenientes del trabajo. Puede argumentarse que esta última es un componente fundamental de la primera, pero que en ningún caso es la única.

Cuando se dice que la desigualdad de América Latina se mantiene tal como era hace medio siglo, o cuando se dice que tal o cual país no ha mejorado en términos de la desigualdad, se está diciendo sólo una parte de la verdad. Puede darse que los indicadores más clásicos de distribución del ingreso permanezcan inalterados, pero ello puede ocurrir al mismo tiempo que una muy significativa disminución de la pobreza, con aumento de coberturas y de calidad en la atención de salud, expansión de la educación y mayor acceso a bienes y servicios.

Por lo tanto, es preciso ser cautelosos a la hora de hacer juicios morales respecto de lo que comúnmente se denomina desigualdad. Sería muy beneficioso para nuestras sociedades y su cohesión social bajar el puntaje del índice de Gini a valores menores que 0,50, y hay que trabajar para ello. Pero también es muy virtuoso reducir a la mitad el porcentaje de familias que viven en la pobreza. ¿Es más deseable una sociedad donde las familias pobres mejoren sustantivamente su acceso a bienes y servicios $\mathrm{u}$ otra donde los ricos ganen menos dinero?

En otras palabras, no hay que confundir la desigualdad de los ingresos con la desigualdad social. Se trata, a fin de cuentas, de que todas las personas puedan acceder a un piso de bienes y servicios, y que los avan-

${ }^{7}$ Sobre esta idea de que “no somos igualmente desiguales”, véase Ottone, E. y C. Pizarro: Osadía de la Prudencia, 2003. 
ces igualitarios se desarrollen hacia arriba, hacia una sociedad igualitariamente más próspera.

El fenómeno de la desigualdad es más complejo que la sola distribución del ingreso. Por ello proponemos la noción de “distribución del bienestar y de las oportunidades”, que permite recoger mejor la compleja realidad de América Latina. Por cierto que hay que procurar una mejor distribución del ingreso, pero también hay que vigorizar los esfuerzos de políticas públicas para lograr una mejor distribución del bienestar y las oportunidades en un sentido más amplio.

\section{LA DISTRIBUCIÓN DEL BIENESTAR Y DE LAS OPORTUNIDADES}

La distribución del bienestar tiene cuatro componentes, y el análisis de cada uno de ellos nos puede dar una visión más precisa de la situación de América Latina.

Estos componentes son:

- El acceso a los bienes de consumo y servicios básicos.

- La evolución de la pobreza.

- El acceso a las oportunidades.

- La distribución del ingreso.

\subsection{El acceso a los bienes}

Los censos de población y vivienda de inicio de los años 80 y comienzo de la década actual muestran aumentos muy apreciables en el acceso de la población a los bienes durables en muchos países latinoamericanos. Bienes tales como heladera, teléfono, teléfonos móviles, televisores, vehículos motorizados, computadores y otros, comienzan a ser accesibles para los sectores más modestos de la población.

Se podría argumentar que, en un sentido estricto, esta nueva accesibilidad no es "en sí” un factor de mayor igualdad, pero ello a partir de un concepto muy reductivo de la igualdad, pues la mayoría de estos bienes no sólo marcan un salto gigantesco en la calidad de vida de las personas, sino que tienen un impacto muy fuerte en la superación de una cierta "línea de civilización” que establece la marginación en una sociedad, vale decir en el ingreso a un mundo compartido, aun cuando desigualmente compartido, pero compartido "en algo".

Para las personas que acceden generacionalmente por primera vez a dichos bienes se trata de un cambio de mundo, que no debe ser subvalo- 
rado y tiene un profundo impacto social en el sentido de "integración” y, a través de los bienes de conectividad, incluso de "inclusión" en el sentido que los define $\mathrm{Cepal}^{8}$.

De otra parte, los Estados aseguran servicios y bienes públicos, algunos de carácter universal y otros focalizados, que aumentan el nivel de bienestar de quienes tienen menos recursos. Ello tiene un impacto muy fuerte en las sociedades y sus avances configuran un fenómeno de "ciudadanía real”. Es universalmente aceptado que los indicadores de mortalidad infantil y de esperanza de vida al nacer son dos indicadores que resumen de buena manera las condiciones de vida y de acceso a servicios de salud y saneamiento.

Se puede apreciar, entonces, que la mejoría de los países latinoamericanos en estos dos indicadores claves muestra un salto notorio entre 1960 y 1980, y que posteriormente muestra una mejoría constante. Cabe señalar que estas mejorías se dan en un contexto de estabilidad de indicadores de desigualdad en la distribución de los ingresos.

FIGURA N ${ }^{\circ}$ 3: $\quad$ EVOLUCIÓN MORTALIDAD INFANTIL.

OCDE - AMÉRICA LATINA

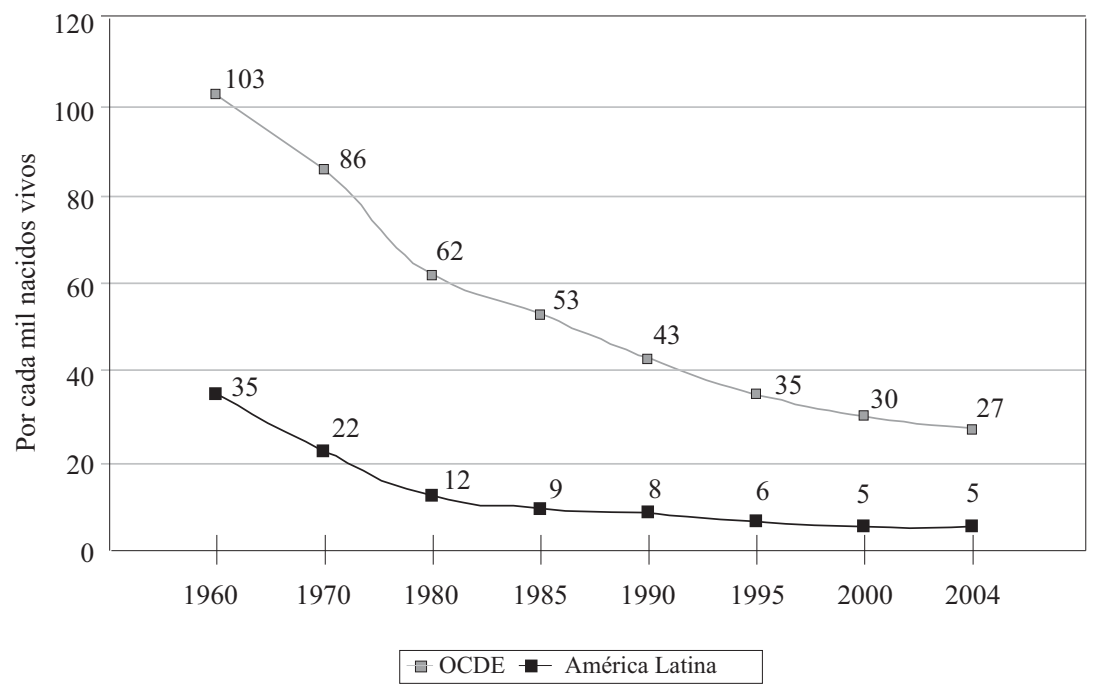

Fuente: Procesamiento especial a partir de datos del World Economic Indicators del Banco Mundial.

${ }^{8}$ Para una visión más detallada, véase Cepal (División de Desarrollo Social): Cohesión Social: Inclusión y Sentido de Pertenencia en América Latina y el Caribe, 2007. 
FIGURA N ${ }^{\circ} 4: \quad$ EVOLUCIÓN DE LA ESPERANZA DE VIDA. OCDE - AMÉRICA LATINA

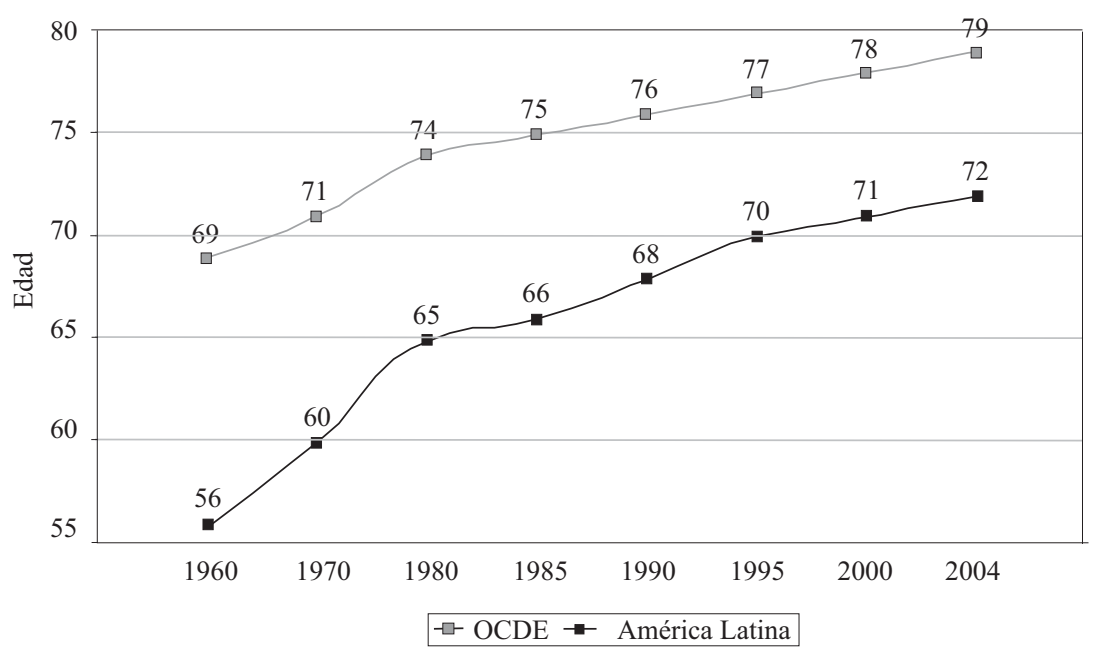

Fuente: Procesamiento especial a partir de datos del World Economic Indicators del Banco Mundial.

\subsection{La evolución de la pobreza}

En América Latina el porcentaje de personas que viven bajo la línea de pobreza ha disminuido, aunque no todo lo que se quisiera. En 1990 la pobreza era de 48,3\% y la extrema pobreza de 22,5\%. En 2006 las cifras son $36,5 \%$ y $13,4 \%$ respectivamente.

Si comparamos las cifras de 2006 con aquellas de 1990 vemos que la tasa de pobreza ha disminuido en 11,8 puntos porcentuales, y la tasa de indigencia en 9,1 puntos porcentuales. La magnitud de estas variaciones se ha traducido en una caída superior a los 20 millones en el número de personas indigentes. Más aun, por primera vez desde ese entonces, el número de personas en situación de pobreza ha logrado situarse por debajo de los 200 millones de personas.

El crecimiento previsto del producto por habitante de los países latinoamericanos para el 2007 permite prever una reducción adicional en los porcentajes de pobreza e indigencia en este año. Dichos indicadores podrían situarse en torno a 35,2\% y 12,7\%, respectivamente, con lo cual el número de personas pobres e indigentes volvería a disminuir, totalizando 

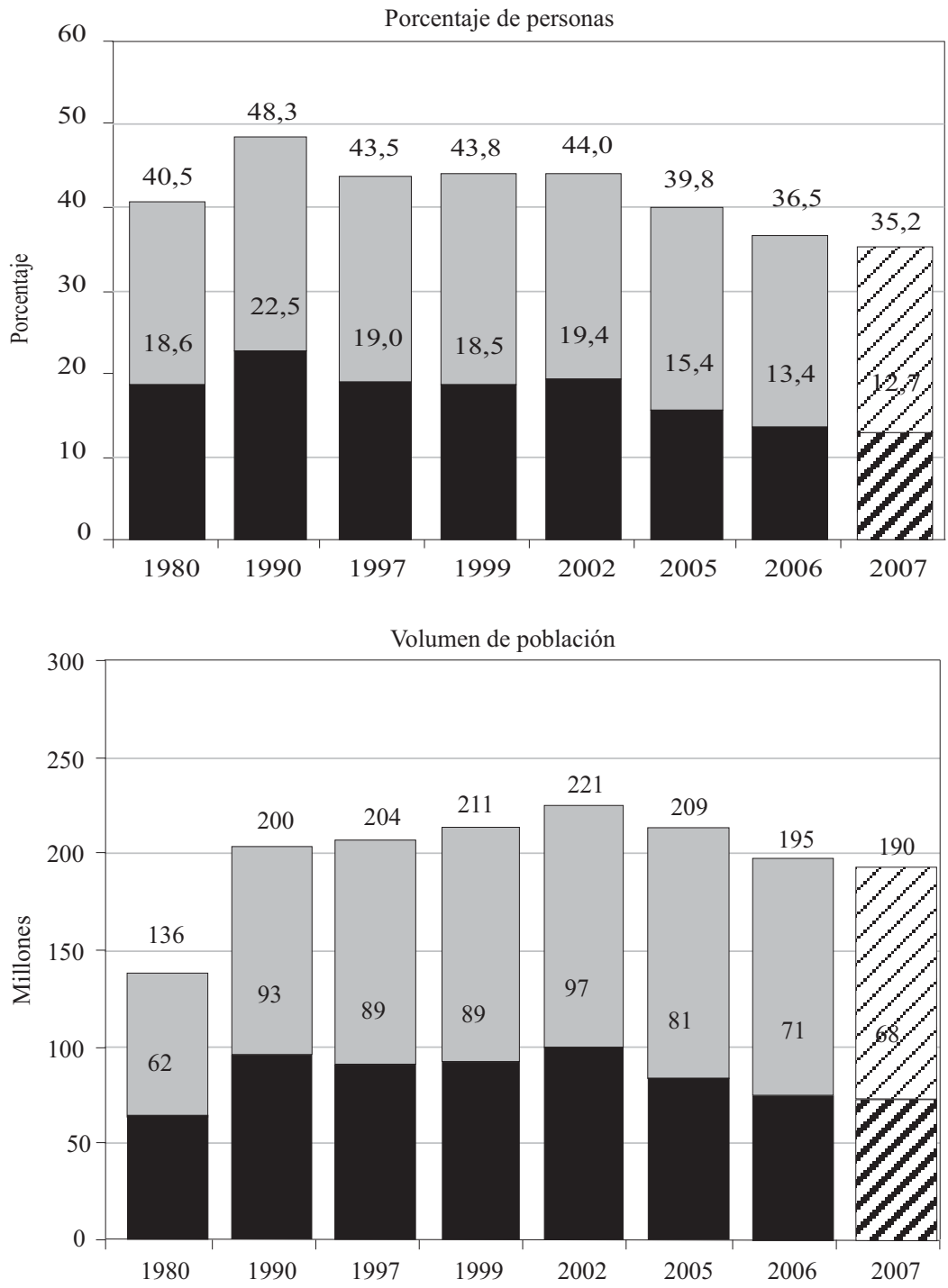

Indigentes $\quad \square$ Pobres no indigentes $\quad \Pi / /$ Proyec. indigentes $\quad / / /$ Proyec. no indigentes

a Estimación correspondiente a 18 países de la región más Haití. Las cifras colocadas sobre las secciones gris claro de las barras representan el porcentaje y número total de personas pobres (indigentes, más pobres no indigentes).

Fuente: Cepal, sobre la base de tabulaciones especiales de las encuestas de hogares de los respectivos países. 
FIGURA N ${ }^{\circ}$ 6: $\quad$ AMÉRICA LATINA (17 PAÍSES): PORCENTAJES DE AVANCE EN LA REDUCCIÓN DE LA POBREZA EXTREMA ENTRE 1990 Y $2007^{\mathrm{a}}$

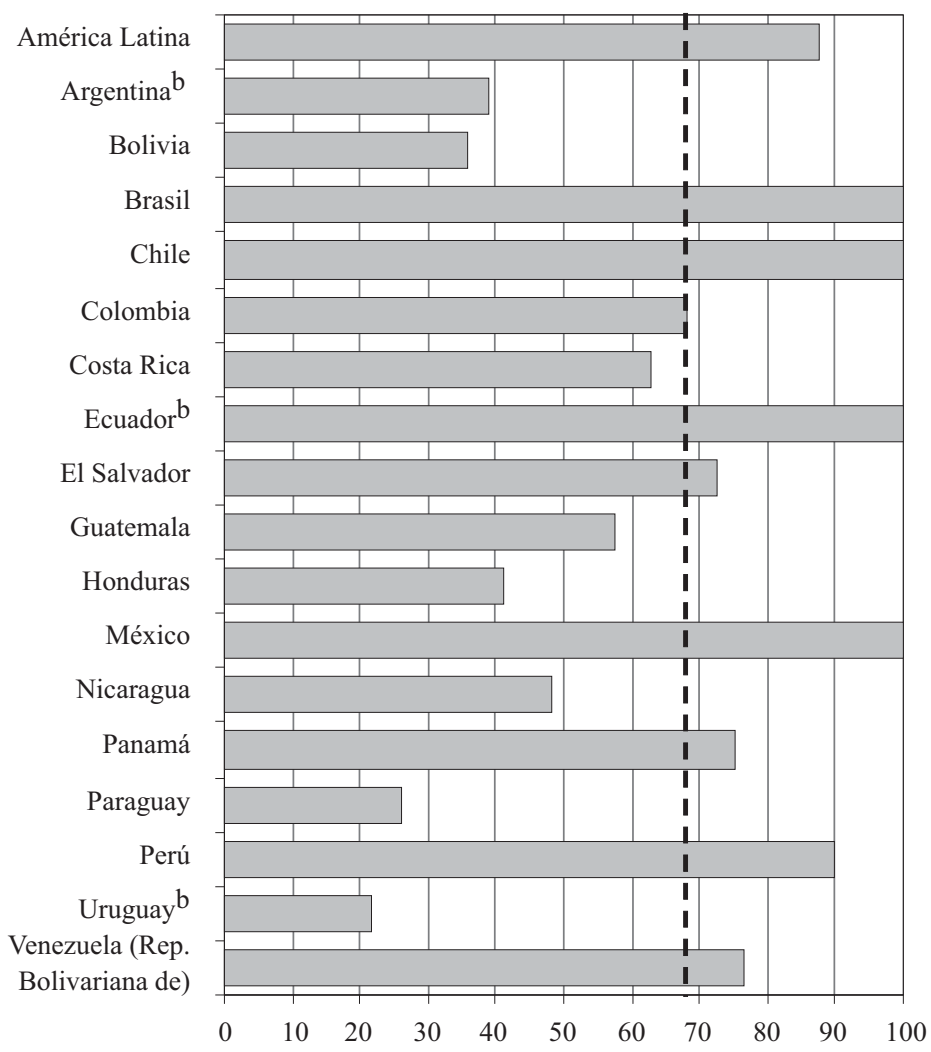

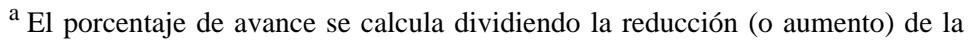
indigencia en puntos porcentuales observada en el período por la mitad de la tasa de indigencia de 1990. Las líneas punteadas representan el porcentaje de avance esperado al 2007 (68\%).

b Áreas urbanas.

Fuente: Cepal, sobre la base de tabulaciones especiales de las encuestas de hogares de los respectivos países.

190 millones y 68 millones respectivamente. Nótese que éstas no sólo serían las tasas más bajas registradas para América Latina desde los años ochenta, sino que representan el menor número de personas en situación de pobreza de los últimos 17 años.

La reducción de la pobreza se logra con una combinación virtuosa de crecimiento alto y sostenido de la economía con políticas públicas efi- 
cientes orientadas a la provisión de servicios de calidad para todos, y con una política fiscal contracíclica que garantice la estabilidad del gasto social cuando el ciclo de la economía viene a la baja.

"Los objetivos del milenio", con los cuales todos los países de América Latina se comprometieron en Naciones Unidas, establecen la reducción de la pobreza en 50\% entre 1990 y 2015. La tasa de pobreza extrema proyectada para América Latina en 2007 alcanza 12,7\%, que es 9,8 puntos porcentuales menos que el nivel de 1990 (22,5\%). Este resultado equivale a un avance de $88 \%$ hacia la consecución de la primera meta del milenio, mientras que el porcentaje de tiempo transcurrido para el cumplimiento de la meta es de $68 \%{ }^{9}$.

Las proyecciones de pobreza extrema al año 2007 dan cuenta de una situación favorable en un conjunto importante de países. Las nuevas cifras para Ecuador (áreas urbanas) y México indican que ambos países lograron situarse junto con Brasil y Chile entre los países que ya cumplieron con la primera meta del milenio. Por su parte, Colombia, El Salvador, Panamá, Perú y la República Bolivariana de Venezuela presentan un progreso similar o superior al esperado (68\%).

\subsection{El acceso a las oportunidades}

La trama principal de la distribución del bienestar está en el acceso a las oportunidades que le permitan a una familia que sus hijos puedan aspirar a condiciones de vida superiores a las que tuvieron los padres. Es necesario romper la actual cadena de transmisión generacional de las oportunidades que se traduce en transmisión generacional de la pobreza, de los empleos precarios y de los bajos ingresos.

Hoy en día, en plena sociedad del conocimiento, la clave central está en la educación.

Sin embargo, la calificación educacional que se requiere para surgir en el mundo de hoy no se logra de un día para otro. Es un proceso que toma su tiempo, que implica la inversión de muchos recursos y que requiere un Estado fuerte y con voluntad política de llevar tal proceso adelante.

América Latina ha logrado más de $90 \%$ de cobertura en la educación primaria y ha doblado la cobertura de la educación secundaria en la última década. Ello nos dice que los latinoamericanos están mucho mejor equipados que hace dos décadas para enfrentar el futuro con probabilidades de

${ }^{9}$ La meta contempla un plazo total de 25 años (desde 1990 hasta 2015), de los cuales han transcurrido 17 , lo que representa un $68 \%$ del tiempo previsto. 
FIGURA N ${ }^{\circ}$ 7: $\quad$ MATRÍCULA EN EDUCACIÓN PRIMARIA Y SECUNDARIA. AMÉRICA CENTRAL-OCDE

Educación primaria

Educación secundaria

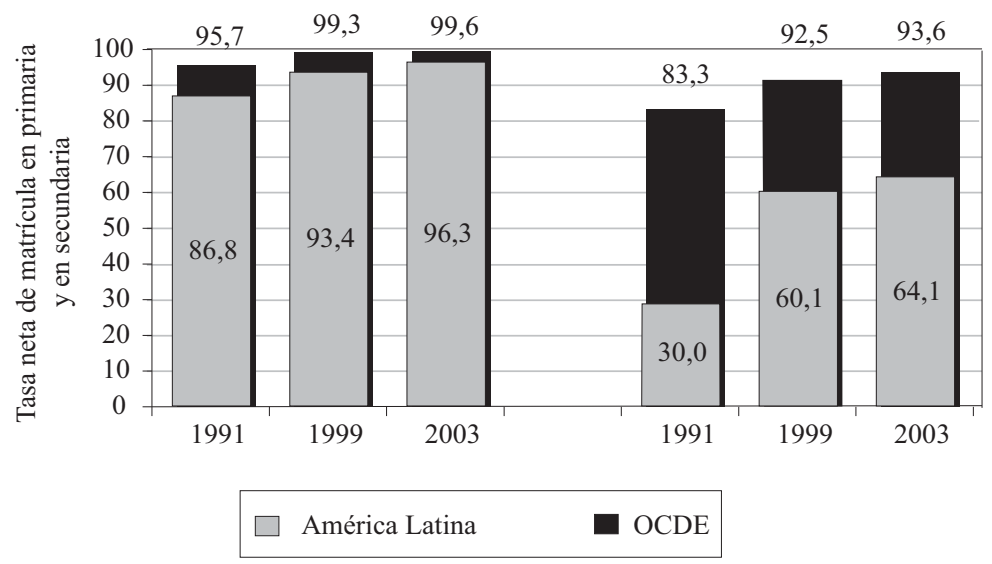

Fuente: Procesamiento especial a partir de datos del World Economic Indicators del Banco Mundial.

éxito, pero también es claro que falta mucho por avanzar. Pero éste no es un proceso lineal. La masificación del sistema educativo conlleva problemas de segmentación por calidad y de desencuentro entre estos avances y la posibilidad limitada de incorporarse a empleos de calidad, con salarios y protección adecuada, lo que genera fuerte frustración, particularmente entre quienes han aumentado significativamente su capital educacional respecto a sus padres. La rapidez del avance del sistema educativo y la lentitud de la oferta de buenos empleos ayuda a la percepción de la injusticia social. Ello plantea nuevos desafíos a los Estados latinoamericanos, los que deben redoblar sus esfuerzos en materia de políticas públicas en educación, conocimiento e innovación tecnológica.

\subsection{La distribución del ingreso}

Ya lo hemos señalado: la distribución del ingreso es históricamente muy desigual en América Latina. De acuerdo con las encuestas de hogares, el $10 \%$ más rico de los individuos recibe entre $40 \%$ y $47 \%$ del ingreso total en la mayor parte de las sociedades latinoamericanas, mientras que el $20 \%$ más pobre sólo recibe entre $2 \%$ y $4 \%$ y, naturalmente, existen altas correla- 
ciones con las desigualdades en educación, salud, saneamiento, electricidad y telefonía, entre otras, como con las discriminaciones de origen étnico y otras formas de adscripción de nacimiento.

Esta persistente desigualdad en la distribución del ingreso resulta ser no sólo una consecuencia de la desigualdad de acceso a patrimonios y activos (tierra, capital físico y social, educación y calificaciones) sino razón de su persistencia.

Todo parece indicar que la globalización ha tenido efectos negativos en la distribución del ingreso en todos los rincones del planeta. Los países desarrollados, con la excepción de Francia y de Holanda, han experimentado un empeoramiento de las desigualdades entre mediados de los 80 y fines de los 90. Incluso países tradicionalmente más igualitarios, como los nórdicos, han empeorado su distribución del ingreso. Los países donde más ha empeorado son Estados Unidos e Inglaterra. Y hay pocas dudas, además, de que este empeoramiento está estrechamente relacionado con los drásticos cambios en la estructura de los mercados de trabajo ${ }^{10}$.

TABLA N $N^{\circ}$ 1: $\quad$ INDICADORES DE DESIGUALDAD PARA ALGUNOS PAÍSES DE AMÉRICA LATINA, ESTADOS UNIDOS E ITALIA

\begin{tabular}{lcccc}
\hline & $\begin{array}{c}\text { Coeficiente } \\
\text { de Gini }\end{array}$ & $\begin{array}{c}\text { Porcentaje } \\
\text { del 10\% } \\
\text { superior en el } \\
\text { ingreso total }\end{array}$ & $\begin{array}{c}\text { Porcentaje } \\
\text { del 20\% } \\
\text { inferior en el } \\
\text { ingreso total }\end{array}$ & $\begin{array}{c}\text { Relación entre } \\
\text { los ingresos } \\
\text { del décimo } \\
\text { decil y el } \\
\text { primer decil }\end{array}$ \\
\hline Brasil (2001) & & & & \\
Guatemala (2000) & 59,0 & $47,2 \%$ & $2,6 \%$ & 54,4 \\
Colombia (1999) & 58,3 & $46,8 \%$ & $2,4 \%$ & 63,3 \\
Chile (2000) & 57,6 & $46,5 \%$ & $2,7 \%$ & 57,8 \\
México (2000) & 57,1 & $47,0 \%$ & $3,4 \%$ & 40,6 \\
Argentina (2000) & 54,6 & $43,1 \%$ & $3,1 \%$ & 45,0 \\
Jamaica (1999) & 52,2 & $39,9 \%$ & $3,1 \%$ & 39,1 \\
República Dominicana (1997) & 52,0 & $40,1 \%$ & $3.4 \%$ & 36,5 \\
Costa Rica (2000) & 49,7 & $38,6 \%$ & $4,0 \%$ & 28,4 \\
Uruguay (2000) & 46,5 & $34,8 \%$ & $4,2 \%$ & 25,1 \\
Estados Unidos (1997) & 44,6 & $33,5 \%$ & $4,8 \%$ & 18,9 \\
Italia (1998) & 40,8 & $30,5 \%$ & $5,2 \%$ & 16,9 \\
\hline
\end{tabular}

Fuente: Banco Mundial: Cuadros A.2 y A.3 del Apéndice Estadístico, Base de Datos de Indicadores de Desarrollo del Banco Mundial.

${ }^{10}$ OCDE: Literacy in the Knowledge Society, 2000. También Atkinson, Robert D.: "Inequality in the New Knowledge Economy", 2005. 
TABLA N ${ }^{\circ}$ 2: $\quad$ CAMBIOS EN LA DISTRIBUCIÓN DE INGRESO DE LOS HOGARES ENTRE LOS AÑOS 80 Y LOS 90

\begin{tabular}{|c|c|c|c|}
\hline & Hog & $\begin{array}{l}\text { bros en } \\
\text { jar }\end{array}$ & $\begin{array}{c}\text { Todos los } \\
\text { hogares }\end{array}$ \\
\hline & \multicolumn{3}{|c|}{ Porcentaje de cambio del coeficiente Gini } \\
\hline & $\begin{array}{l}\text { Ingreso del } \\
\text { trabajo }\end{array}$ & $\begin{array}{c}\text { Ingreso } \\
\text { disponible }\end{array}$ & $\begin{array}{c}\text { Ingreso } \\
\text { disponible }\end{array}$ \\
\hline Bélgica (85-96) & +2 & +5 & +10 \\
\hline Francia (84-94) & -1 & -2 & 0 \\
\hline Alemania (Occ.) (84-94) & +25 & +33 & +7 \\
\hline Italia (86-95) & +17 & +15 & +13 \\
\hline Holanda (87-94) & -5 & -2 & -5 \\
\hline Dinamarca (87-97) & +12 & +4 & +1 \\
\hline Finlandia (87-95) & +29 & +16 & +4 \\
\hline Noruega (86-95) & +23 & +4 & +7 \\
\hline Suecia (87-95) & +25 & +1 & +12 \\
\hline Inglaterra (86-95) & +9 & +14 & +28 \\
\hline EE.UU. (86-95) & +11 & +10 & 24 \\
\hline
\end{tabular}

Edad de trabajar: 25 a 55 años. Mientras más grande el número, mayor es el cambio hacia la desigualdad.

Fuente: Cuadro tomado de Esping-Andersen: "Inequality of Incomes and Opportunities”, 2005.

No deja de ser impresionante el impacto de los Estados de bienestar sobre la estructura de los ingresos. La desigualdad entre el ingreso proveniente del trabajo (o del mercado) y aquella del ingreso disponible (después de los impuestos y beneficios) es muy significativa, particularmente en el caso de los países escandinavos. La tesis que postula la acción del Estado como el principal corrector de las desigualdades que genera el mercado se muestra como altamente eficiente.

La información disponible muestra que este aumento en la desigualdad se puede deber a dos fenómenos: a un mayor enriquecimiento de los segmentos que ya eran ricos, pero que ello no afecta las condiciones de los más pobres; o bien, a una polarización que se produce además por una pérdida de los segmentos más pobres.

Un rasgo particular de esta desigualdad distributiva en América Latina es la elevada fracción que capta el 10\% más alto de la población. Mientras en los países europeos el ingreso del 10\% de la cúpula supera en no 
TABLA No 3: $\quad$ AMÉRICA LATINA (18 PAÍSES): ESTRATIFICACIÓN DE PAÍSES SEGÚN EL COEFICIENTE DE GINI DE LA DISTRIBUCIÓN DEL INGRESO, 1998/1999$2003 / 2005^{\mathrm{a}}$

\begin{tabular}{|c|c|c|c|c|c|c|}
\hline \multirow{3}{*}{$\begin{array}{l}\begin{array}{l}\text { Nivel de } \\
\text { desigualdad }\end{array} \\
\text { Muy alto } \\
0,580 \text { - } 1\end{array}$} & \multicolumn{2}{|c|}{ 1998/1999 } & \multicolumn{2}{|c|}{$2000 / 2002$} & \multicolumn{2}{|l|}{$2003 / 2005$} \\
\hline & Brasil & 0,640 & Brasil & 0,639 & Bolivia (2002) & 0,614 \\
\hline & Bolivia & 0,586 & Bolivia & 0,614 & Brasil & 0,613 \\
\hline & Nicaragua & 0,584 & Honduras & 0,588 & Honduras & 0,587 \\
\hline & & & & & Colombia & 0,584 \\
\hline Alto & Colombia & 0,572 & Nicaragua & 0,579 & Nicaragua (2001) & 0,579 \\
\hline \multirow[t]{9}{*}{$0,520-0,579$} & Paraguay & 0,565 & Argentina $^{\mathrm{b}}$ & 0,578 & Rep. Domin. & 0,569 \\
\hline & Honduras & 0,564 & Paraguay & 0,570 & Chile & 0,550 \\
\hline & Chile & 0,560 & Colombia & 0,569 & Guatemala (2002) & 0,542 \\
\hline & Guatemala & 0,560 & Chile & 0,559 & Paraguay & 0,536 \\
\hline & Rep. Domin. & 0,554 & Rep. Domin. & 0,544 & México & 0,528 \\
\hline & Perú & 0,545 & Guatemala & 0,542 & Argentina $^{b}$ & 0,526 \\
\hline & Argentina $^{\mathrm{b}}$ & 0,539 & El Salvador & 0,525 & & \\
\hline & México & 0,539 & Perú & 0,525 & & \\
\hline & Ecuador ${ }^{b}$ & 0,521 & Panamáb & 0,515 & & \\
\hline Medio & El Salvador & 0,518 & México & 0,514 & Ecuador $^{\mathrm{b}}$ & 0,513 \\
\hline \multirow{3}{*}{$0,470-0,519$} & Panamáb & 0,513 & Ecuadorb & 0,513 & Perú & 0,505 \\
\hline & $\begin{array}{l}\text { Rep. Bol. de } \\
\text { Venezuela }\end{array}$ & 0,498 & Venezuela & 0,500 & Panamáb & 0,500 \\
\hline & Costa Rica & 0,473 & Costa Rica & 0,488 & $\begin{array}{l}\text { El Salvador } \\
\text { Rep. Bol. de } \\
\text { Venezuela }\end{array}$ & $\begin{array}{l}0,493 \\
0,490\end{array}$ \\
\hline $\begin{array}{l}\text { Bajo } \\
0-0,469\end{array}$ & Uruguay $^{\mathrm{b}}$ & 0,440 & Uruguay $^{\mathrm{b}}$ & 0,455 & $\begin{array}{l}\text { Costa Rica } \\
\text { Uruguayb }^{b}\end{array}$ & $\begin{array}{l}0,470 \\
0,451\end{array}$ \\
\hline
\end{tabular}

a Los valores límite del índice de Gini para cada categoría son los mismos que se emplearon en el capítulo I del Panorama Social de América Latina 2004. Éstos se determinaron empleando el algoritmo de estratificación estadística de las k-medias, que busca generar estratos que sean homogéneos en su interior pero a la vez presenten la máxima variabilidad posible entre ellos.

b Áreas urbanas.

Fuente: Comisión Económica para América Latina y el Caribe (Cepal), sobre la base de tabulaciones especiales de las encuestas de hogares de los respectivos países.

más de $20 \%$ ó 30\% el ingreso del noveno decil, en América Latina esa distancia es de más de 100\% y en algunos casos de más de 200\%.

Las cifras de distribución del ingreso en América Latina correspondientes a los años 2003-2005 muestran una incipiente mejoría. De acuerdo a la Cepal, en ocho países de la región la relación entre el 10\% más rico y el $40 \%$ más pobre registró una disminución, se mantuvo en dos y aumentó sólo en cuatro. 
La desigualdad distributiva en América Latina encuentra su mayor causalidad en la relación de los mercados de trabajo con los niveles educacionales, pues los ingresos laborales constituyen más de dos tercios del ingreso total de los hogares. Sobre la base de las encuestas de hogares en torno al 2002, un estudio reciente realizado en zonas urbanas de 13 países de América Latina reveló que los ingresos laborales representan el 81\% del ingreso total de los hogares ${ }^{11}$.

De esta manera, si se estudian en profundidad las variables que determinan el nivel de los ingresos laborales y su dispersión, podremos avanzar de manera sustantiva en la comprensión del fenómeno de la distribución del ingreso y de las políticas públicas que se requieren para hacerla más equitativa.

En este estudio la desigualdad de los salarios se mide a partir de la varianza del logaritmo de los salarios por hora. Este indicador alcanza un

FIGURA N ${ }^{\circ}$ 8: $\quad$ AMÉRICA LATINA (13 PAÍSES): PARTICIPACIÓN DE LOS INGRESOS DEL TRABAJO Y LOS SALARIOS EN EL INGRESO TOTAL, ALREDEDOR DE 2002 (Áreas urbanas)

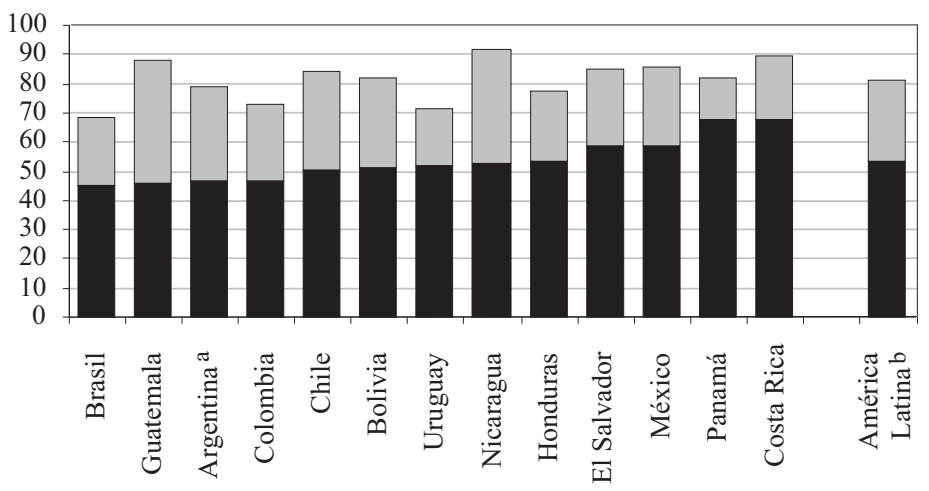

- Salarios $\square$ Otros ingresos del trabajo

${ }^{\text {a }}$ Gran Buenos Aires.

b Promedio simple.

Fuente: Cepal, sobre la base de tabulaciones especiales de las encuestas de hogares de los respectivos países.

${ }^{11}$ Cepal: Panorama Social de América Latina, 2006. 
valor promedio de 0,65 para los países analizados, lo que muestra un alto nivel de desigualdad distributiva ${ }^{12}$.

El panorama de desigualdad que muestra este indicador de varianza del logaritmo de los salarios por hora coincide en términos gruesos con el del índice de Gini, pero pone de manifiesto ciertas diferencias ${ }^{13}$.

Argentina, por ejemplo, muestra la menor desigualdad salarial y se encuentra en el punto medio del índice de Gini; por su parte, Uruguay muestra la distribución más equitativa del ingreso medida por el índice de Gini y se ubica en la media de la desigualdad salarial.

Lo que cabe destacar, en todo caso, es que la evolución de la desigualdad salarial entre 1990 y 2002 tiene dos rasgos importantes. En primer lugar, el estancamiento de la desigualdad a nivel regional; y en segundo lugar, una menor dispersión (la desviación estándar baja de 0,19 a 0,12 entre 1990 y 2002). Hay un deterioro en la desigualdad salarial en países como Uruguay y Costa Rica, a la vez que un mejoramiento en países como Brasil y Colombia.

Sabemos entonces que los salarios representan el $81 \%$ del ingreso familiar en las zonas urbanas de América Latina. Sabemos, además, que la desigualdad salarial es, en promedio, bastante más alta que en los países desarrollados. Sabemos, por último, que la desigualdad salarial tiende a mantenerse en los mismos niveles de una década atrás y que, además, tiende a ser más homogénea entre los países de la región.

¿De qué depende, entonces, el nivel de los salarios?

El análisis de la descomposición de la varianza salarial permite concluir que la educación es el factor que más contribuye a la dispersión de los salarios en América Latina.

El incremento en el salario como retribución a un año adicional de estudio (tasa de retorno de la educación) promedió 0,14 en los países anali-

12 De acuerdo a una muestra que considera doce países: Reino Unido, Estados Unidos, España, Canadá, Francia, Alemania, Holanda, Finlandia, Austria, Suecia, Noruega y Dinamarca, este indicador alcanza un valor promedio en torno a 0,20. Véase Bertola, G., F. Blau y L. Kahn: "Comparative Analysis of Labor Market Outcomes: Lessons for the US from International Long-Run Evidence”, 2001.

${ }^{13}$ Existen diversas razones por las que cabe esperar cierta discordancia entre la distribución de los ingresos y la de los salarios. Entre ellas cabe mencionar, por una parte, las diferencias entre los hogares de distintos estratos en cuanto a su tamaño medio y número de perceptores. En un hogar de gran tamaño y escaso número de perceptores un nivel dado de salario por ocupado generará un ingreso per cápita menor que en un hogar más pequeño y con mayor número de ocupados. Por otra parte, los índices de desigualdad utilizados tienen propiedades distintas. El coeficiente de Gini asigna una mayor ponderación a las observaciones situadas en la parte media de la distribución, mientras que la varianza de los logaritmos otorga una mayor importancia relativa a la parte baja de la distribución. 
FIGURA N ${ }^{\circ}$ 9: $\quad$ AMÉRICA LATINA (13 PAÍSES): POSICIÓN RELATIVA DE LOS PAÍSES DE ACUERDO AL ÍNDICE DE GINI Y A LA VARIANZA DEL LOGARITMO DE LOS SALARIOS POR HORA, ALREDEDOR DE 2002 (Áreas urbanas) $^{\mathrm{a}}$

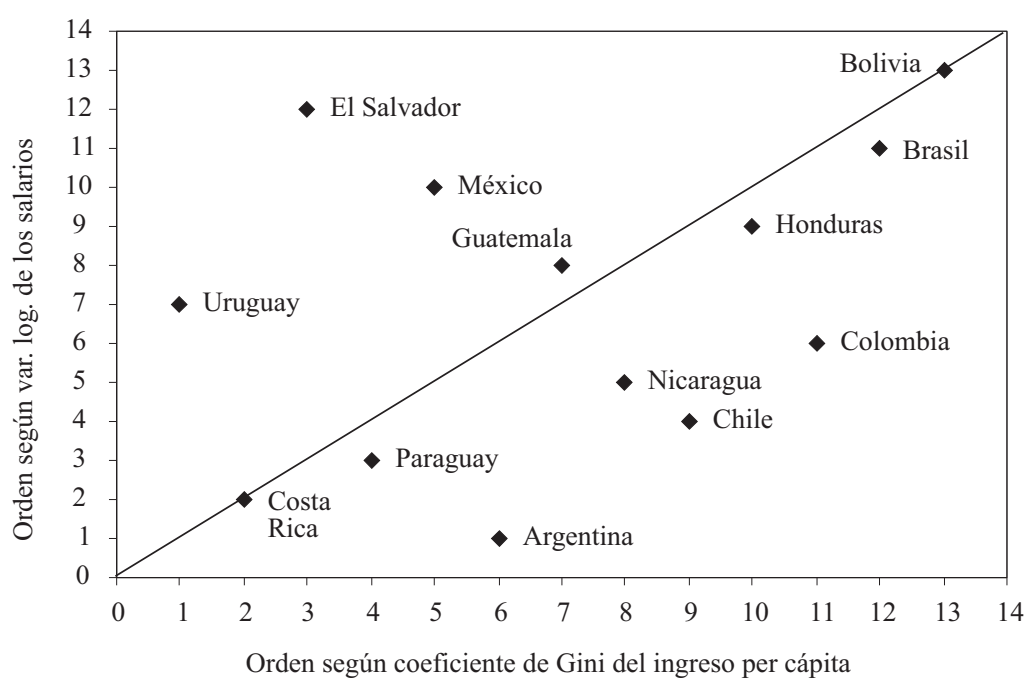

${ }^{a}$ Los datos de Argentina corresponden al Gran Buenos Aires y los de Bolivia a ocho ciudades principales más El Alto.

Fuente: CEPAL, sobre la base del trabajo de Dante Contreras y Sebastián Gallegos (2006), "Descomponiendo la Desigualdad Salarial en América Latina: ¿Una década de cambios?”, inédito.

zados con información en torno a 2002. Entre 1990 y 2002 no se registraron variaciones en la tasa de retorno de la educación, tanto en términos regionales promedio como en los países en particular.

Sin embargo, hay cambios significativos según los niveles educacionales. Los retornos de la educación primaria y secundaria mostraron un movimiento opuesto al de la educación superior. En efecto, el retorno de la educación primaria pasó, en promedio, de 0,09 a 0,08, y el de la secundaria de 0,14 a 0,12 . En cambio, el retorno de la educación superior pasó de 0,15 a 0,18 . Se amplió, entonces, la brecha entre la tasa de retorno de la educación superior y la secundaria: mientras en torno a 1990 eran relativamente similares $(0,14$ y 0,15), hacia el año 2002 tienden claramente a diferenciarse $(0,12$ y $0,18)$.

Si en la base de la desigualdad salarial está la educación, específicamente la educación postsecundaria, entonces el camino a recorrer para dis- 
minuir las desigualdades salariales está en la inversión en cobertura y calidad de la educación que se ofrece.

Así como en las áreas de acceso a bienes y servicios, de disminución de la pobreza y de expansión de oportunidades, para corregir la desigualdad de ingresos no hay atajos ni caminos cortos. El proceso de lograr una mayor igualdad distributiva es quizás el más lento si el propósito es, como nosotros pensamos, igualar "hacia arriba”, asegurar el camino democrático y preservar las libertades individuales.

\section{EL CASO DE CHILE}

La experiencia chilena, a partir de la recuperación de la democracia, si bien es considerada exitosa en materia de crecimiento (la economía creció a un ritmo de 4,2\% por habitante entre 1990 y el 2005) y de disminución de la pobreza, es criticada por su incapacidad de reducir en forma significativa los niveles de desigualdad en la distribución del ingreso. Para tener una visión más equilibrada sobre los éxitos y los no éxitos de esta experiencia, es conveniente comparar las cifras de Chile en torno a 1989-1990 con aquellas en torno a 2004-2005, y así analizar la realidad chilena a la luz de los cuatro componentes de la desigualdad que hemos propuesto. ¿Es el Chile de hoy tan inequitativo como el de fines de los 80 ? ¿Será que no ha habido mejorías en igualdad en general, o será que ello queda circunscrito más bien a la distribución del ingreso?

\subsection{Acceso a bienes y servicios}

En poco más de una década, la población más pobre de Chile duplicó su ingreso monetario y multiplicó por cuatro su acceso a bienes y servicios fundamentales.

Si se observa la evolución del PIB per cápita de Chile y se le compara con el conjunto de América Latina es posible concluir que el país ha tenido un progreso visible en materia de ingresos de las familias a partir de 1990 .

Sería un error pensar que este crecimiento del ingreso de los chilenos sólo favorece a los más ricos y que los más pobres no se han beneficiado de aquello.

Si comparamos las cifras del Censo de 1992 con las del Censo de 2002, podemos apreciar la dirección y la magnitud de los cambios que han ocurrido en la sociedad chilena. 
FIGURA No 10: $\quad$ EVOLUCIÓN DEL PIB PER CÁPITA EN AMÉRICA LATINA Y CHILE. PPA US\$ Constantes 2000

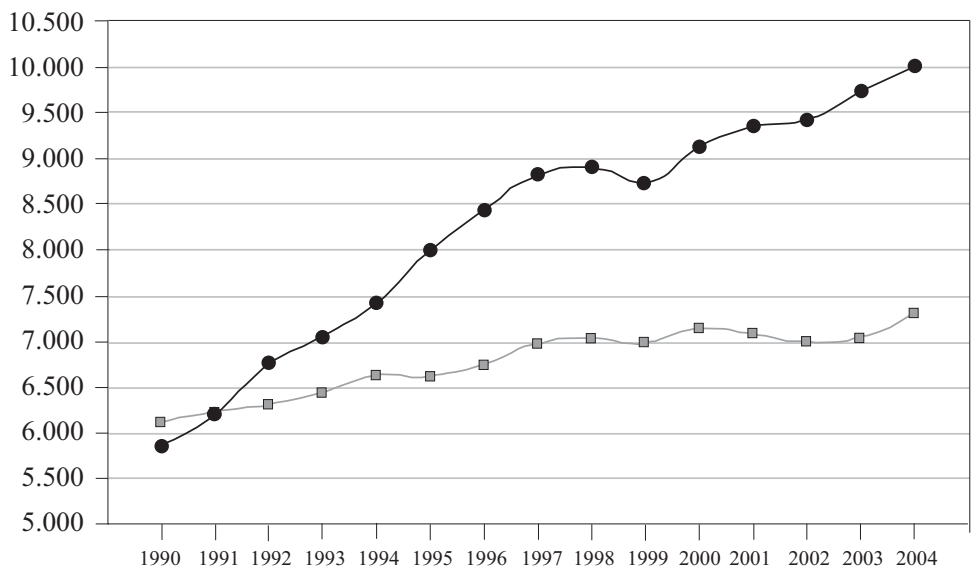

Chile - $\square$ América Latina y el Caribe

Fuente: Procesamiento especial a partir de datos del World Economic Indicators del Banco Mundial.

Las familias pobres de Chile son las que más se han beneficiado de este progreso. En una comuna pobre del Gran Santiago, La Pintana, los hogares con refrigerador crecieron en $117 \%$ en esos diez años. En Tirúa, una comuna rural del sur de Chile, los hogares que cuentan con lavadora han crecido en $955 \%$ en esa década.

TABLA N ${ }^{\circ}$ 4: $\quad$ PORCENTAJE DE ACCESO A BIENES Y SERVICIOS BÁSICOS DEL 20\% DE LA POBLACIÓN MÁS POBRE. CENSOS NACIONALES 1992-2002 ${ }^{\mathrm{a}}$

\begin{tabular}{lcc}
\hline & 1992 & 2002 \\
\hline Máquina lavadora programable & 0,3 & 46 \\
Refrigerador & 8 & 45 \\
Electricidad & 50 & 83 \\
Agua potable & 40 & 63 \\
Alcantarillado & 5 & 57 \\
\hline
\end{tabular}

a Éstas son cifras nacionales. Ahora bien, de acuerdo con datos del CEP, Estudio de Opinión Pública $\mathrm{N}^{\circ} 41$ de junio de 2001, para el 20\% más pobre de la población urbana el agua potable llega al 95,5\% y el sistema de alcantarillado al 84,2\%.

Fuente: Censos Nacionales 1992, 2002. 
En buena medida el mayor acceso a bienes se debe a que, desde 1990, ha habido un aumento significativo de los ingresos de los sectores más pobres del país.

Es evidente que ha habido una democratización del acceso a bienes que se obtienen en el mercado. Entre 1990 y 2004, el salario mínimo creció en un 70,1\% real. En 1990 la remuneración promedio de un profesor de escuela, por 44 horas, era de 272 mil pesos mensuales; en 2005 es de 699 mil pesos, es decir, $157 \%$ de aumento real.

Pero también el Estado ha generado políticas públicas orientadas a un mayor bienestar de los sectores más pobres ${ }^{14}$. Sólo a modo de ejemplo podemos señalar que el aumento acumulado del gasto público en vivienda, salud, y educación entre 1990 y 2000 fue de 164\%, 247\% y 274\% respectivamente ${ }^{15}$.

Así, por ejemplo, en Chile, en una década disminuyó en 43\% el número de viviendas deficitarias; el 75\% de los chilenos vive en casa propia; más del 90\% de las viviendas son permanentes, cuentan con energía eléctrica, agua potable y alcantarillado.

Se diseñó e implementó la Reforma Procesal Penal; se implementó una reforma laboral importante y se creó un seguro de desempleo. Entre 2000 y 2004 se entregaron 2.844 nuevas escuelas, lo que equivale a 1,5

$\begin{array}{ll}\text { TABLA N } & \text { 5: } \\ & \text { NIVEL SOCIOECONÓMICO BAJO } \\ & \text { ¿CÓMO HAN MEJORADO LOS INGRESOS EN } 10 \text { AÑOS? (1990-2001) } \\ & \text { (Muestras urbanas) (En pesos de diciembre de 2000) }\end{array}$

(Muestras urbanas) (En pesos de diciembre de 2000)

\$ mensuales líquidos $\quad$ Septiembre $1990 \quad$ Junio 2001

$\begin{array}{lrr}\text { Hasta \$ 78.000* } & 54,7 & 13,5 \\ \text { Entre \$ 79.000 y \$ } 134.000^{*} & 29,8 & 26,7 \\ \text { Entre \$ } 135.000 \text { y \$ 224.000* } & 9,1 & 29,0 \\ \text { Entre \$ 225.000 y \$ 358.000* } & 2,5 & 13,3 \\ \text { Más de \$ 358.000* } & 2,1 & 5,4 \\ & & 12,1\end{array}$

* Diferencia estadísticamente significativa entre mediciones de sept. y junio 2001.

Fuente: CEP (Centro de Estudios Públicos): encuestas de septiembre 1990 y de junio 2001.

${ }^{14}$ Para una visión más detallada de la gestión del Estado a favor de los sectores más pobres, ver Ottone, E. y C. Vergara, Ampliando Horizontes, 2006.

${ }^{15}$ Solimano, A. y M. Pollack, La Mesa Coja, 2006. 
escuelas por día; se extendió la jornada escolar completa a prácticamente todo el país; en los últimos 15 años las colaciones diarias para los escolares se incrementaron en $350 \%$. Se aumentaron casi en $150 \%$ los recursos para la atención primaria de salud entre 1999 y 2005.

Los consultorios cuentan hoy con exámenes de rayos, análisis de laboratorio y consultas de especialidad. Se diseñó y empezó a aplicar el plan de Régimen de Garantías Explícitas que implica atención universal y oportuna para 56 patologías que dan cuenta del $80 \%$ de todas las intervenciones hospitalarias en Chile.

Los sectores más pobres multiplican el acceso a bienes que se adquieren en el mercado a la vez que multiplican el acceso a servicios que son provistos por el Estado por medio de políticas públicas especialmente diseñadas para ello.

\subsection{La pobreza}

En quince años de democracia, la pobreza se redujo de $38,6 \%$ a 13,7\%. Y la indigencia de 13,0\% a 3,2\%. No hay otro país de América Latina que haya disminuido sus niveles de pobreza e indigencia en la magnitud y profundidad que lo ha hecho Chile en este período de su historia ${ }^{16}$.

\subsection{Las oportunidades}

Tal como se ha dicho anteriormente, las posibilidades de acceder a empleos de mejor calidad, y por tanto a mejores remuneraciones, están dadas fundamentalmente por el nivel educacional de las personas. Ya se ha mostrado que la educación es la variable fundamental en la determinación del salario, y que las tasas de retorno de la educación terciaria son las que mayor crecimiento han mostrado en la última década.

¿Qué ha ocurrido en Chile al respecto?

En Chile la educación obligatoria es ahora de doce años. Entre 1990 y 2003 la cobertura de educación preescolar creció de 1,9\% a 30,3\% en el primer quintil, y de $17,5 \%$ a $34 \%$ en el segundo; se ha alcanzado cobertura universal en la educación primaria, y entre 1990 y 2003 la cobertura de la

${ }^{16}$ Incluso en los años de mayores dificultades económicas (2000-2003) la elasticidad de la reducción de la pobreza respecto al crecimiento del PIB llegaba a un valor de 1,93. Vale decir, por cada punto de crecimiento del PIB, la pobreza se reducía en casi dos puntos. Al respecto, véase Ottone, Ernesto y Carlos Vergara: “Concertación por la Democracia: Progressivism in Practice”, 2004. 
FIGURA N ${ }^{\circ}$ 11: $\quad$ POBREZA E INDIGENCIA

Chile 1990-2006

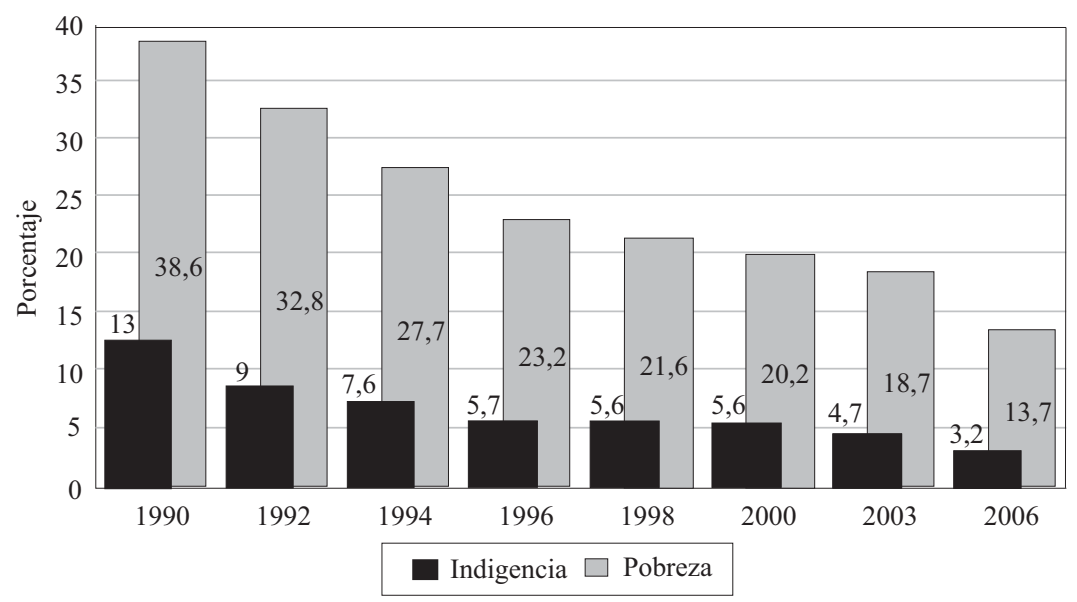

Fuente: Mideplan: Cifras oficiales de la encuesta Casen.

educación secundaria se expandió de 73,3\% a 87,5\% en el primer quintil, y de $76,3 \%$ a $91,7 \%$ en el segundo. Los jóvenes de los hogares más pobres tienen 2,5 veces más educación que sus abuelos y 1,5 veces más que sus padres $^{17}$.

Ya hemos visto que la tasa de retorno es mayor en la educación terciaria. Una persona con educación universitaria gana 3 veces más por hora que una con educación secundaria, y 5,2 veces más que una con educación primaria.

Un 70\% de los nuevos estudiantes del sistema de educación superior (universidades, institutos profesionales, centros de formación técnica) son primera generación en sus respectivas familias en alcanzar este nivel educacional. Y más de un tercio de los nuevos estudiantes universitarios son también primera generación. Esto constituye un cambio social de enorme profundidad en la sociedad chilena. La cobertura de educación superior, entre 1990 y 2003, creció de 4,4\% a 14,5\% en el primer quintil, y de 7,8\% a 21,2\% en el segundo.

Cierto es que los jóvenes de los dos quintiles más altos son quienes tienen la más alta cobertura en educación superior, particularmente en la

17 Tokman, Víctor: “Globalization in Chile: A Positive Sum of Winners and Loosers”, 2006. 
universitaria. Allí reside en parte importante la actual desigualdad de ingresos del trabajo. Se requiere entonces intensificar la transformación educacional, aumentando la cobertura en la educación preescolar y terciaria, y aumentar la calidad educacional cuyas deficiencias siguen siendo notorias. Sólo así aumentarán las oportunidades en una dirección meritocrática e igualitaria.

\subsection{La distribución del ingreso}

El 80\% del ingreso de las personas proviene del trabajo, y dicho ingreso está muy desigualmente distribuido. Es claro, además, que la concentración del ingreso tiene raíces históricas De acuerdo a datos de Larrañaga ${ }^{18}$ de 2001 correspondientes al Gran Santiago, el período de máxima concentración del ingreso se da entre 1980 y 1990, cuando el ingreso promedio del quintil más rico es más de 20 veces superior al del quintil más pobre.

A partir de 1990 se empieza a revertir esa situación. Si tomamos en consideración el conjunto del país en base a la encuesta Casen ${ }^{19}$, podemos observar que la situación se estabiliza en un rango entre 14 y 15, y en el año 2006 muestra una mejoría importante.

FIGURA N N $^{\circ}$ 12: RAZÓN DE INGRESOS AUTÓNOMOS, QUINTIL 5 - QUINTIL 1

Chile 1990-2006

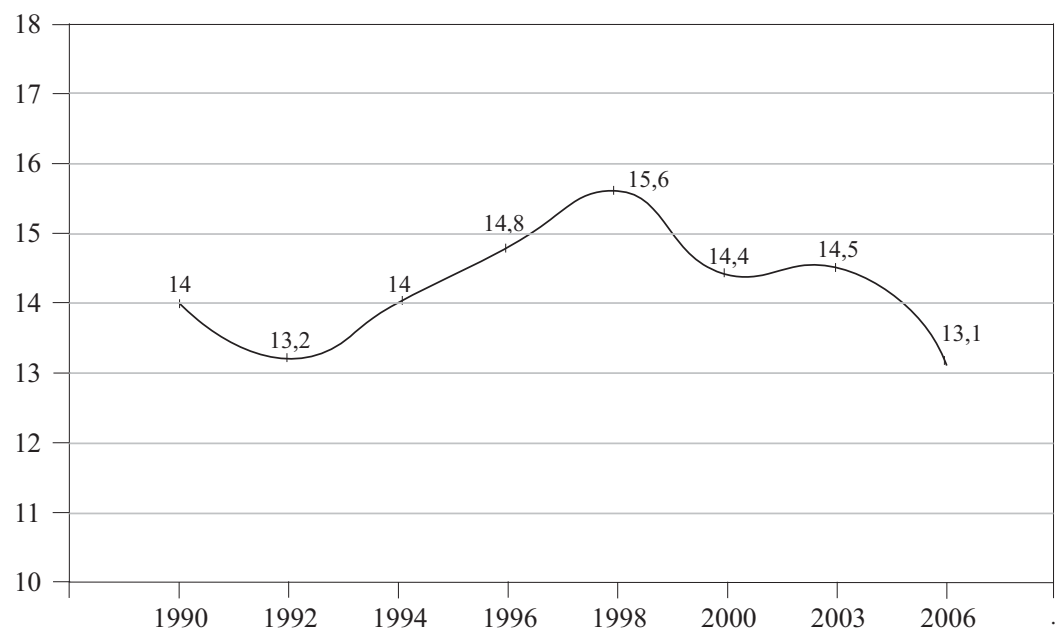

Fuente: Mideplan: Encuesta Casen.

${ }^{18}$ Larrañaga, Osvaldo: “Distribución de Ingresos 1958-2001”, 2001.

${ }^{19}$ Encuesta de hogares disponible sólo a partir de 1987. 
TABLA N ${ }^{\circ} 6$

$\begin{array}{lr}\text { Ingreso autónomo } & 13,1 \\ \text { Ingreso monetario } & 11,2 \\ \text { Ingreso total } & 6,8\end{array}$

Fuente: Mideplan: Cifras oficiales de la encuesta Casen.

Esta medida se construye sobre la base de los ingresos autónomos. Sin embargo, si incorporamos las transferencias monetarias y los subsidios de educación y salud, la relación de ingresos entre ambos quintiles mejora sustantivamente.

Ello da cuenta de la enorme importancia de contar con políticas públicas eficientes y eficaces, orientadas a mejorar la calidad de vida y las oportunidades de la gente más pobre.

FIGURA N ${ }^{\circ}$ 13: $\quad$ PARTICIPACIÓN DEL INGRESO AUTÓNOMO Y SUBSIDIOS EN EL INGRESO TOTAL (POR DECILES DE INGRESO AUTÓNOMO)

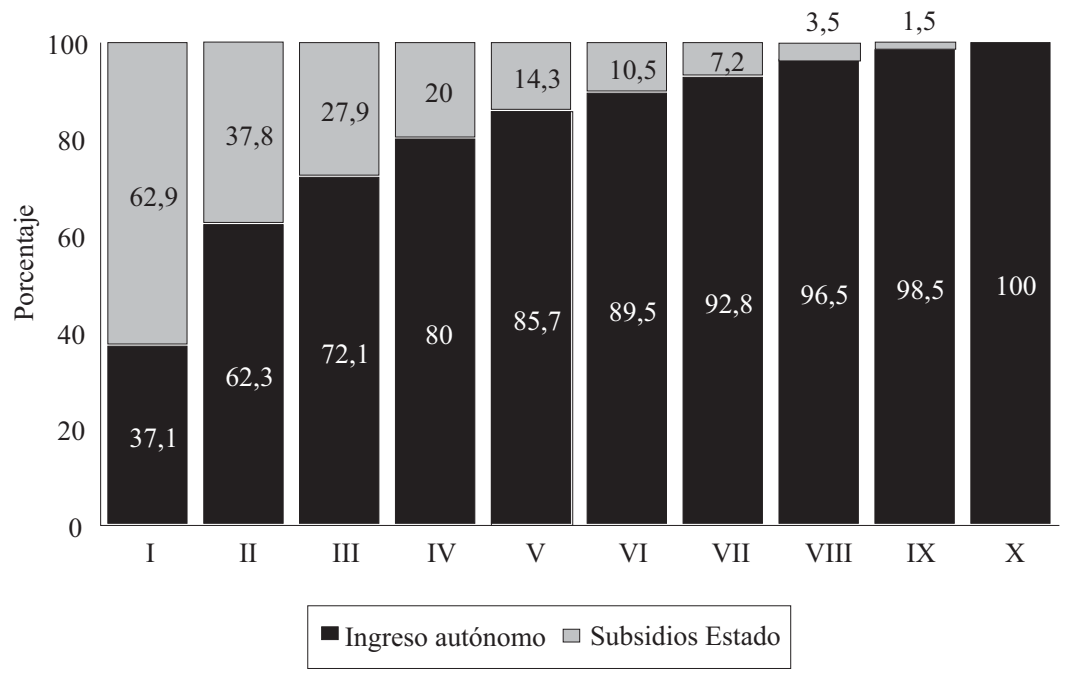

Fuente: Mideplan: Encuesta Casen 2006. 
Ahora bien, todo parece indicar que, al igual que en muchos países industrializados ${ }^{20}$, en el caso de Chile se produce también una concentración del ingreso en el 5\%, y más aún en el 1\% superior de la distribución. Si el coeficiente de Gini es calculado excluyendo el decil de más altos ingresos, la distribución mejora significativamente y Chile se convierte en un país con mayores niveles de igualdad.

Si consideramos la evolución más histórica del coeficiente de Gini, asunto en el cual hay que tener mucho cuidado por los problemas de comparabilidad de los datos, podemos observar que no hay cambios muy acentuados desde los años 50 en adelante.

El nivel más bajo observado, en el período 1970-73, es siempre muy superior al de cualquier país desarrollado de la OCDE.

Desde mediados de 1960, el gobierno desarrollista de Eduardo Frei Montalva, pasando por la experiencia del gobierno socialista de Salvador Allende, siguiendo con el gobierno militar de Pinochet, y luego con ya casi 17 años de democracia y en el cuarto gobierno de la misma coalición política

FIGURA No 14 : ÍNDICE DE GINI.

Gran Santiago 1957-1996

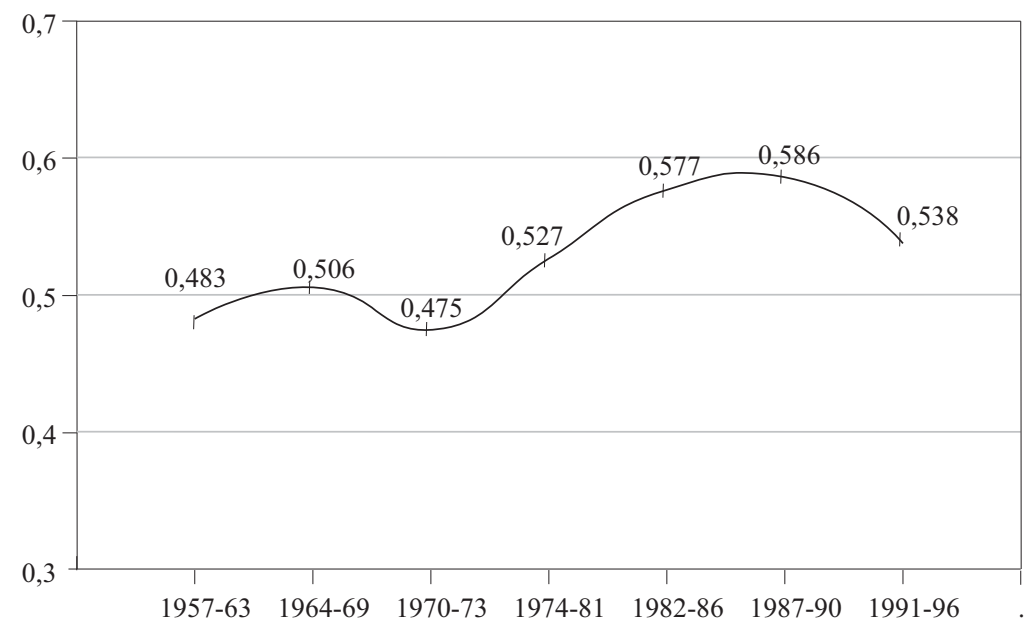

Fuente: Larrañaga, O.: “Distribución de Ingresos 1958-2001”, 2001.

${ }^{20}$ Véase Esping-Andersen, Gosta: "Inequality of Incomes and Opportunities”, 2005. 
(Concertación por la Democracia), vemos que el índice de Gini no tiene variación significativa, más o menos entre 0,48 (1972) y 0,54. Cuarenta años de historia, cuatro tipos de gobiernos radicalmente diferentes, políticas económicas absolutamente distintas, y en la práctica el índice de Gini se mantiene en niveles muy altos ${ }^{21}$.

En definitiva, la información disponible nos muestra que Chile, a partir de 1990, recorre un camino positivo en materia de acceso a bienes y servicios, de reducción enorme de la pobreza y de la indigencia, de expansión de oportunidades de los sectores más pobres. Sin embargo, estos avances no tienen un correlato en lo que se refiere a la distribución de los ingresos provenientes del trabajo, no se ven reflejados en el índice de Gini, y por lo tanto - el uso exclusivo de este indicador para medir desigualdad general - genera una imagen distorsionada del desarrollo económico y social de Chile de los últimos años.

Lo anterior no significa predicar una cierta complacencia con los actuales niveles de desigualdad de ingresos de la sociedad chilena. Sería muy absurdo. Pero todo indica que el camino de la reformas —largo, perse-

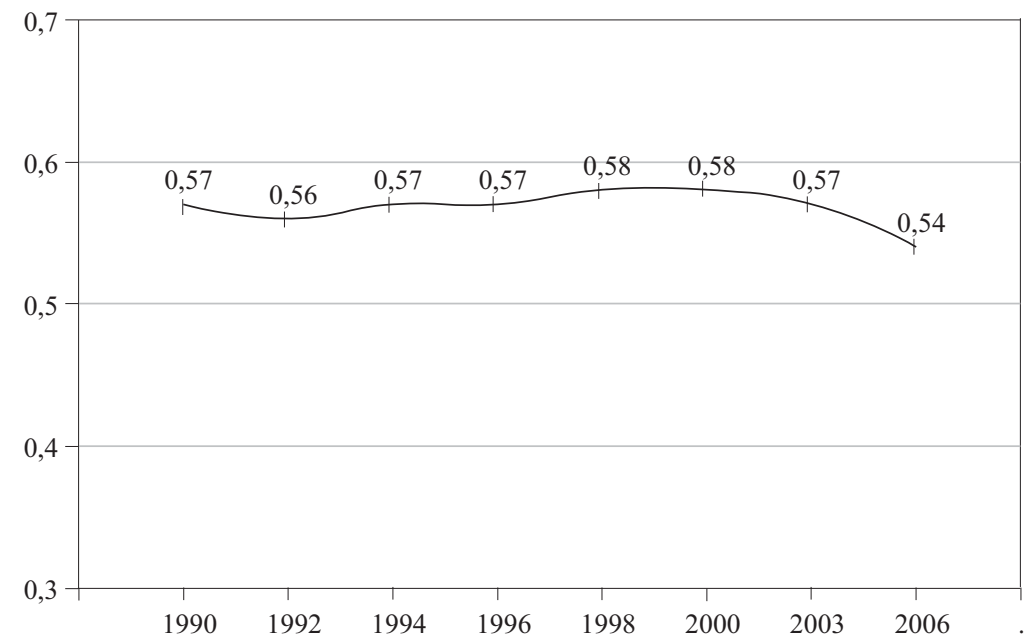

Fuente: Mideplan, Encuesta Casen.

${ }^{21}$ El promedio de los países de la OCDE es de 0,32. 
verante y sin falsos atajos - permite avanzar hacia mayores niveles de igualdad y bienestar, al mismo tiempo que se consolidan las libertades individuales y el sistema democrático.

Expandir las oportunidades es la igualdad del futuro; reducir aún más la pobreza es el desafío presente. Ambas tareas requieren de políticas públicas claras, eficientes, transparentes. Y con recursos públicos suficientes para financiarlas. Todos estos factores conducen a una mayor cohesión social, con énfasis en las oportunidades basadas en la educación y el conocimiento, que constituyen bienes fuertemente expansibles.

\section{CONCLUSIÓN}

¿Es posible disminuir esta escurridiza desigualdad de los latinoamericanos? La respuesta no es fácil, pues hemos visto que el problema de la igualdad es muy complejo incluso en países desarrollados y con una base de origen más igualitaria.

La respuesta es más compleja aún si consideramos como valores indivisibles la democracia, la libertad individual y la igualdad, y por lo tanto descartamos los atajos populistas y autoritarios, que suelen traducirse en experiencias que están más cerca de las pesadillas que de los sueños que los vieron nacer.

Sin embargo, creemos que es posible avanzar hacia una región más igualitaria y algunos elementos constitutivos de ese camino aparecen señalados en este trabajo.

Caminar hacia sociedades más igualitarias pasaría por un “mejor” crecimiento que pueda generar empleos de mejor calidad, por políticas económicas contracíclicas que eviten la volatilidad, que siempre hace que pierdan los más débiles en los ciclos negativos, por un pacto fiscal que permita aumentar la baja carga tributaria de la región de manera progresiva, por desarrollar políticas públicas eficientes y sólidas frente a los grupos de presión. Pasaría también por una institucionalidad fuerte capaz de reducir el arbitrio de los hombres y aumentar la eficacia de las reglas evitando así la corrupción.

Pasaría de manera muy central por aumentar los accesos a la propiedad y otros activos, pero en primer lugar, para que los avances sean auténticos y definitivos, se trataría sobre todo de igualar el acceso a una educación de calidad que permita quebrar el bloqueo a un desarrollo igualitario del capital humano, redistribuyendo las capacidades en base al mérito y 
destruyendo la base desigual de origen que ha marcado la historia de América Latina.

Detrás de este camino gradual pero persistente subyace en definitiva la idea de que el éxito de la región debe medirse por el nivel de dignidad de vida de los menos favorecidos, más que por las cifras promedio.

Una región donde, incluso asumiendo la conceptualización tan en boga de "ganadores” y "perdedores", los primeros puedan tener su recompensa, pero también los segundos tengan asegurado su nivel de dignidad humana y sus hijos tengan las oportunidades que les permitan llegar a ser, a su vez, ganadores si tienen el talento y mérito para serlo.

\section{REFERENCIAS}

Atkinson, Robert D.: “Inequality in the New Knowledge Economy”. En Anthony Giddens y Patrick Diamond, The New Egalitarianism. Cambridge, UK.: Polity Press, 2005.

Banco Mundial: Base de datos de Indicadores de Desarrollo. Varios años.

Bertola, G., F. Blau y L. Kahn: "Comparative Analysis of Labor Market Outcomes: Lessons for the US from International Long-Run Evidence”. NBER working paper $\mathrm{N}^{\circ}$ 8526, 2001.

Bobbio, Norberto: El Futuro de la Democracia. México: Fondo de Cultura Económica, 1986, primera edición.

CEP (Centro de Estudios Públicos): Encuestas de opinión de septiembre de 1990 y junio de 2001. [En www.cepchile.cl]

Cepal (Comisión Económica para América Latina y el Caribe): Base de datos, varios años.

- Panorama Social de América Latina. Cepal, 2006.

- Cohesión Social: Inclusión y Sentido de Pertenencia en América Latina y el Caribe. Dirección de Ernesto Ottone y coordinación de Ana Sojo. Cepal, 2007.

Contreras, Dante y Sebastián Gallegos: "Descomponiendo la Desigualdad Salarial en América Latina: ¿Una Década de Cambios?”. Inédito, s/f.

Esping-Andersen, Gosta: “Inequality of Incomes and Opportunities”. En Anthony Giddens y Patrick Diamond, The New Egalitarianism. Cambridge, UK.: Polity Press, 2005.

Feres, Juan Carlos y Carlos Vergara: "Hacia un Sistema de Indicadores de Cohesión Social en América Latina”. En Ana Sojo y Andrés Uthoff (eds.), Cohesión Social en América Latina y el Caribe: Una Revisión Perentoria de Alguna de sus Dimensiones. Cepal, febrero 2007.

Halperin Dongui, Tulio: Conferencia pronunciada en la Cepal con ocasión de la Séptima Cátedra Raúl Prebisch, agosto 2007.

Larrañaga, Osvaldo: “Distribución de Ingresos 1958-2001”. En Ricardo French-Davis y Bárbara Stallings (eds.), Reformas, Crecimiento, y Políticas Sociales en Chile desde 1973. CEPAL, noviembre 2001. 
Machinea J. L. y M. Hopenhayn: "La Esquiva Equidad en el Desarrollo Latinoamericano. Una Aproximación Estructural, una Aproximación Multifacética”. En Informes y Estudios Especiales, № 14, Cepal, 2005.

Mideplan (Ministerio de Planificación, Gobierno de Chile): Encuesta Casen, varios años. OCDE: Literacy in the Knowledge Society. OCDE, 2000.

Ottone, E. y C. Pizarro: Osadía de la Prudencia. FCE, 2003.

Ottone, Ernesto y Carlos Vergara: “Concertación por la Democracia: Progressivism in Practice”. En Progressive Politics, Vol. 3.3, October 2004, London. - Ampliando Horizontes. Random House Mondadori, 2006.

Sen, Amartya: Identitá e Violenza. Roma, Bari: Editori Laterza, 2006.

Solimano, A. y M. Pollack: La Mesa Coja. LOM, 2006.

Squella, Agustín: Norberto Bobbio: Un Hombre Fiero y Justo. Fondo de Cultura Económica, 2005.

Tokman, Víctor: “Globalization in Chile: A Positive Sum of Winners and Loosers”. Por publicarse. 